\title{
Optimization of process parameters in turning of nuclear grade steel alloy (AISI-410) for sustainable manufacture
}

\author{
Anis Fatima*, Muhammad Wasif and Muhammad Omer Mumtaz \\ Department of Industrial and Manufacturing Engineering, NED University of Engineering and Technology, Karachi-75270, Pakistan. \\ *Corresponding Author: anisf@neduet.edu.pk
}

Submitted :01/08/2020

Revised :26/05/2021

Accepted :05/06/2021

\begin{abstract}
Metal cutting operations involve intense heat generation owing to plastic deformation of the work piece and due to friction at the tool-work piece and tool-chip interface. The heat generated in metal cutting unfavourably affects the quality and thus the functional performance of the product. It is known that quality and functional performance is the function of roughness and dimensional accuracy. To maintain a longer component life, along with the robust material choice, a component should have good surface finish and dimensional accuracy. While, for the organization to monitor and control their environmental issues in a holistic manner, emphasis in adopting ecofriendly practices and protecting environment has been growing continuously across all the business sectors. In this study, an attempt is made to optimize the process parameter of stainless steel AISI-410 alloy, a nuclear grade material, for better surface finish. For this, Taguchi L9 orthogonal array was utilised to identify the process parameter and cutting environment. Analysis of variance (ANOVA) was also conducted to highlight the significant parameter that affects the surface finish the most. A statistical model to forecast the surface roughness was also developed and was validated by an experiment with a maximum error of $12 \%$. Results indicate that feed rate is the most critical factor that affects the surface roughness with the contribution of $91.5 \%$, followed by environment with $5.22 \%$ contribution, cutting speed, and depth of cut with $2.7 \%$ and $0.4 \%$, respectively. The correlation coefficient of 0.9213 and conformation tests reveals that developed statistical model predicts surface roughness with the statistical error limit.
\end{abstract}

Keywords: Functional performance; Optimisation; Surface roughness; Sustainable manufacture; Taguchi design.

\section{INTRODUCTION}

To satisfy challenging design and functional requirements, the production of super alloys and smart materials has become the need for industries like chemical, nuclear, aerospace industries, and so on. However, the processing of such materials is yet another challenge. The focus of modern day manufacturing is on productivity and the high quality. The concept of increasing productivity is revolutionized by the invention of computer numerically controlled (CNC) machines. High quality originates relative to surface finish and dimensional 
precision of the product. Till date, mechanical machining is the fundamental manufacturing process to convert materials into required shape and size to meet designated functional purpose. Mechanical machining involves processes, such as milling, drilling, grinding, and turning. Regardless of operation, the surface finish of the machined part is mainly determined by the machining parameter and the generated heat.

On the other hand, the concept of sustainable manufacturing has received huge significance due to the growing awareness of environmental issues. In the context of manufacturing processing, sustainability is defined as the processing of products that use methods that reduce waste, shrink harmful environmental impacts, save energy, protects natural resources, and are safe for staff and society (Dassisti et al., 2012). Sustainable manufacturing needs a strong knowledge of both sustainability concepts and the process itself. Hence, it is important to optimize the process for reduced resource utilization, toxic wastes, and health hazards, and alike it improves the quality of products. It is argued that this can be achieved by changing the machining parameters for improved process output (Lanz et al., 2010; Liyanage et al., 2009; YUCEL and GUNAY, 2013).Therefore, sustainable factors, such as total cost and resources associated with cutting process related to the purchase, maintenance, and disposal together with the health and safety hazards, have pushed researchers to discover ways for reducing the amount of resource required for cutting altogether (Astakhov, 2012; Dwuletzki, 2012; Evans, 2012; Graff, 2012).

The philosophy of Taguchi has been widely used in optimization of process parameters and response variables. It is a technique of Design of Experiment (DOE) that is often used for the cost, time, and material saving. It has been extensively used to optimize the performance characteristics of manufacturing processes in machining of various alloys. However, much of the work is conducted for the applications in aerospace industries and manufacturing in general.

Advanced materials that are industrialised for high strength and heat resistant applications are categorised as difficult to cut materials (Venkatesan et al., 2014). This is due to the high machining cost associated with their processing. Specifically in nuclear industries, the functional requirements, harsh environment, and growing material and processing cost have put pressure on researchers to find sustainable ways of processing components that are used in nuclear industries. To date, a limited number of studies have been led in nuclear grade materials. Zhang et al. (Zhang et al., 2007) optimize surface quality of Aluminium in milling using Taguchi method. The control factors for the study were spindle speed, feed rate, and depth of cut, while the chamber temperature and different tool inserts (condition and dimensional variability) were considered noise factors. It was established that feed and speed are the influencing factors on surface finish. Deepak and Rajendra (Deepak and Rajendra, 2016) established that the most influential process parameter on the surface roughness is the feed rate in turning of A16061. It was noted that both studies focus on the components of aerospace industry. Qasim et al (Qasim et al., 2015) optimize the process for surface roughness, power consumption, and temperature using several cutting tools. An orthogonal machining was performed on AISI 1045 steel material. The analysis of variance (ANOVA) and the finite element simulation were also conducted to confirm that the feed rate and the depth of cut are the most persuasive factors on power. Also, the cutting speed and rake angle were demonstrated to be the most significant on the cutting temperature. Nalbant et al (Nalbant et al., 2007) optimise machining performance in turning of AISI1030 steel bars. It was established that cutting radius of cutting insert and feed is the main factor to control the surface roughness of the machined surface. Ghani et al. (Ghani et al., 2004) performed the Taguchi experiment in milling of hardened steel $\mathrm{H} 13$ for finishing operation and found that speed and feed are the main parameters to affect the surface finish and the cutting forces. Mustafa et al. (Ay, 2019) conduct optimisation study on AISI $316 \mathrm{Ti}$ steel for reduced tool vibration and surface roughness. It was explored that cutting speed was a dominant factor for tool vibration and feed for the surface roughness. Karunya et al. (Karunya et al., 2017) optimise surface roughness of AISI 304 austenitic stainless concerning to the cutting environment. Generation of excess heat/temperature in machining of AISI 304 was the criteria for optimisation. It was recognised that cutting speed significantly contributed, and the contribution was of $62 \%$. Singh et al. (Singh, 2019) executed Taguchi design optimization of 
AISI 304 for enhanced tool life and surface finish. Vegetable oil based cutting fluids were used, and cutting speed was identified as a significant parameter as a regulator for enhanced tool life and surface finish in machining of AISI 304. Serif et al. (Çetin and Kıvak, 2017) investigated the effect of speed, feed and depth of cut on cutting forces and surface roughness in turning of 15-5 PH martensitic stainless steel. It was originated that depth of cut affects the cutting forces, while feed contributed most in roughness. Selvaraj et al. (Selvaraj and Chandramohan, 2010) also optimized the surface characteristics of AISI 304 in dry turning. Feed rate and cutting speed were identified as the critical factors to ascertain the surface roughness.

It is evident from the literature review that few studies are focussed on the machining of nuclear grade material. Till date, no study focuses on AISI 410. This grade of steel (AISI 410) is used in the control rod drive mechanism of pressurized water type reactors. Therefore, there is a high need to address the sustainable way of machining this nuclear grade material. This research is significant in terms of selecting process parameters that can sustainably manufacture a nuclear grade component and is a step furthering the efforts towards sustainable indigenization. This research could also be beneficial to be used as turning database for related industries for improved machining and cost-saving.

\section{MATERIAL AND METHODS}

Cutting tests were performed on TOPPER TNL-100AL, horizontal spindle lathe machining centre. Tool holding system was PCLNR 2525-M12.TiCN+A12O3+TiN coated cutting inserts by Brand Kyocera (CNMG120408MS) were used as a cutting tool. The TiCN+Al2O3+TiN coated inserts were selected because it is cost effective and suites both rough and finish machining. AISI 410 alloy steel was the work material. It is a stabilized martensitic stainless steel and has a wide range of applications in the nuclear industry. It has excellent mechanical and corrosion resistance qualities that are the key requirement for nuclear procedures (Waseem et al., 2017).Work piece dimensions were diameter equals to $42 \mathrm{~mm}$ and length equals to $40 \mathrm{~mm}$. The cutting fluid used was commercial water-soluble mineral oil by Blasocut (swizz lube). MQL is delivered to the cutting zone through the UNIST Uni-MAX colubricator system. The MQL flow rate of $50 \mathrm{ml} / \mathrm{h}$ was selected as per pump restriction. The MQL system provides air at a positive displacement stroke adjustment of $0.03 \mathrm{ml} / \mathrm{stroke}$. The fluid flow rate for wet conditions was 45 litres/min. Taguchi's L9 orthogonal array was selected to explore the consequence of machining parameter on the surface finish. Factors, levels, and experimental trials are shown in Table 1 below. All the machining tests were randomly repeated three times. Surface roughness was measured by Mitutoyo roughness tester type SJ-210.

Table 1. Taguchi $L 9$ orthogonal array.

\begin{tabular}{|c|c|c|c|c|}
\hline Levels & \multicolumn{4}{|c|}{ Factors } \\
\hline Run & $\begin{array}{c}\text { Cutting Speed, } \\
\boldsymbol{V}_{\boldsymbol{c}}(\mathbf{m} / \mathbf{m i n})\end{array}$ & $\begin{array}{c}\text { Feed rate, } \\
\boldsymbol{f}(\mathbf{m m} / \mathbf{r e v})\end{array}$ & $\begin{array}{c}\text { Depth of cut, } \\
\boldsymbol{a}_{\boldsymbol{p}}(\mathbf{m m})\end{array}$ & Environment \\
\hline 1 & 50 & 0.1 & 0.4 & dry \\
\hline 2 & 50 & 0.2 & 0.8 & wet \\
\hline 3 & 50 & 0.3 & 1.2 & mql \\
\hline 4 & 90 & 0.1 & 0.8 & mql \\
\hline
\end{tabular}




\begin{tabular}{|c|c|c|c|c|}
\hline 5 & 90 & 0.2 & 1.2 & dry \\
\hline 6 & 90 & 0.3 & 0.4 & wet \\
\hline 7 & 125 & 0.1 & 1.2 & wet \\
\hline 8 & 125 & 0.2 & 0.4 & mql \\
\hline 9 & 125 & 0.3 & 0.8 & dry \\
\hline
\end{tabular}

\section{RESULT AND DISCUSSION}

Table 2 presents the experiment results. The table is generated in accordance with Taguchi's orthogonal L9 array. Contributing parameters were speed, feed, depth of cut, and cutting environment, while the reaction was surface roughness. It shows the mean values and signal-to-noise ratio for each combination. To minimize the variability caused by the noise factors, $S / N$ ratios were calculated, and all calculation was performed on software Minitab 16.0. Negative $S / N$ ratio specifies that the noise factors are greater than the signal factors during the machining process.

Table 2. Experimental Results.

\begin{tabular}{|c|c|c|c|c|c|c|c|c|c|}
\hline \multicolumn{5}{|c|}{ Factors } & \multicolumn{5}{|c|}{ Response $(R a-\mu m)$} \\
\hline Run & $\begin{array}{c}V_{c} \\
(m / m i n)\end{array}$ & $f(m m / r e v)$ & $a p(m m)$ & Environment & $\begin{array}{c}\text { Trail } \\
1\end{array}$ & $\begin{array}{c}\text { Trail } \\
2\end{array}$ & $\begin{array}{c}\text { Trail } \\
\mathbf{3}\end{array}$ & Mean & $\begin{array}{c}S / N \\
\text { Ratio }\end{array}$ \\
\hline 1 & 50 & 0.1 & 0.4 & Dry & 1.43 & 1.407 & 1.302 & 1.35 & -2.60668 \\
\hline 2 & 50 & 0.2 & 0.8 & Wet & 1.491 & 1.88 & 2.147 & 1.839 & -5.29163 \\
\hline 3 & 50 & 0.3 & 1.2 & MQL & 3.016 & 3.141 & 3.112 & 3.089 & -9.79636 \\
\hline 4 & 90 & 0.1 & 0.8 & MQL & 0.987 & 0.964 & 0.992 & 0.981 & 0.16662 \\
\hline 5 & 90 & 0.2 & 1.2 & Dry & 2.102 & 2.148 & 1.65 & 2.102 & -6.45265 \\
\hline 6 & 90 & 0.3 & 0.4 & Wet & 3.006 & 2.758 & 3.112 & 2.958 & -9.41996 \\
\hline 7 & 125 & 0.1 & 1.2 & Wet & 0.384 & 0.447 & 0.844 & 0.5583 & 5.062647 \\
\hline 8 & 125 & 0.2 & 0.4 & MQL & 1.352 & 1.383 & 1.36 & 1.365 & -2.70265 \\
\hline 9 & 125 & 0.3 & 0.8 & Dry & 3.162 & 3.435 & 3.27 & 3.289 & -10.3413 \\
\hline
\end{tabular}

Taguchi technique suggests three classifications of $S / N$ ratio: larger-the-better, medium-the-better, and smaller-the-better. In this case, smaller-the-better was considered as imperative to achieve good quality; the surface roughness has to be the minimum. The mean signal to noise ratio for each trial was calculated by using Minitab software, and results are revealed in Table 3. 
Table 3, Response Table for Signal to Noise Ratio,

\begin{tabular}{|c|c|c|c|c|}
\hline Level & $\begin{array}{c}\text { Cutting Speed } \\
(\mathbf{m} / \mathbf{m i n})\end{array}$ & $\begin{array}{c}\text { Feed Rate } \\
\mathbf{( m m} / \mathbf{r e v})\end{array}$ & $\begin{array}{c}\text { Depth of Cut } \\
\mathbf{( m m})\end{array}$ & Environment \\
\hline 1 & -5.8982 & 0.8742 & -4.9098 & -6.4669 \\
\hline 2 & -5.2353 & -4.8156 & -5.1554 & -3.2163 \\
\hline 3 & -2.6604 & -9.8525 & -3.7288 & -4.1108 \\
\hline Delta & 3.2378 & 10.7267 & 1.4266 & 3.2506 \\
\hline Rank & 3 & 1 & 4 & 2 \\
\hline
\end{tabular}

In Table 3, delta is the difference between the highest and lowest average responses and is used to assigned ranks to the factors. Table 3 represents that feed rate has the most significant and leading effect on the surface roughness followed by cooling environment, cutting speed, and depth of cut. Figure 1 represents the main effects plot. The plot is used to match the comparative strength of the effects of the factors and also to show the deviation of individual response with the four parameters, that is, cutting speed, feed, depth of cut, and environment. The xaxis represents the process parameter at three levels, and the y-axis indicates the response. Central horizontal line depicts the mean value of the response. The main effect of a factor may be described as the average change in response generated by the change in the level of a factor studied. It is evident from Figure 1 that feed rate is the main factor that affects the surface finish the most, while the depth of cut has the minimum affect. The optimum setting for minimum surface finish occurs at the minimum points in Figure 3. This means that feed rate of 0.1 $\mathrm{mm} / \mathrm{rev}$, cutting speed of $125 \mathrm{~m} / \mathrm{min}$, depth of cut of $1.2 \mathrm{~mm}$, and wet environment is ideal for machining AISI 410 at the current setting.

AISI 410 belongs to the family of steel, which is the ductile material and develops build-up edge (BUE) that results in deprived surface finish. BUE is the result of high temperature and friction occurring in the machining of ductile materials. The results are in accordance with the established theory that for such materials high speed and low feed rates are required (Debnath et al., 2016; Xavior and Adithan, 2009). Also, in the case of BUE, the flooded (wet) cutting condition is ideal to decrease the cutting temperature and friction at primary and secondary machining zones (Debnath et al., 2016). This explains the significance of results achieved in this study. 


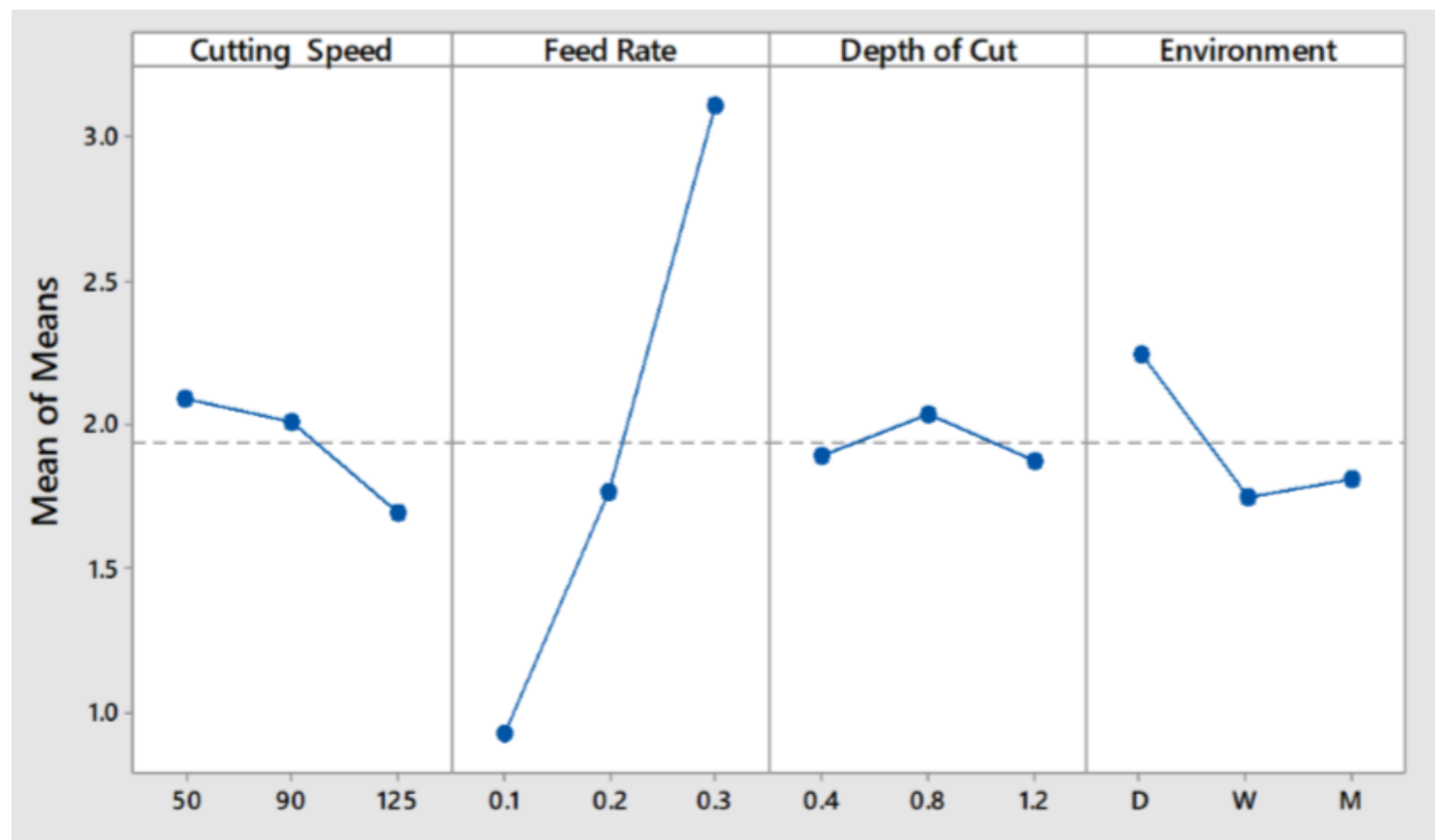

Figure 1. Main effect plot for means.

Analyses of Variance (ANOVA) evaluate the prominence of factors by associating the average response of the individual variable at the different factor levels. In generals, analysis of Variance (ANOVA) is performed to identify the most substantial and influential process parameter on response (in this case, surface roughness). The analysis was carried out at $95 \%$ confidence level $(\alpha=0.05)$ on Minitab Software. ANOVA results are given below in Table 4. From Table 4, it is evident that, statistically, in machining AISI 410, only feed rate is a substantial parameter that affects the surface finish with the contribution of $91.5 \%$. However, the next contributing factor is cutting environment (5.22\% contribution), while cutting speed ( $2 \%$ contribution) has a little effect on a surface finish. The results interpret that that surface finish is merely a function of feed rate. Shaw et al. (Shaw and Cookson, 2005) had established that if corner radius (in this case it was $0.8 \mathrm{~mm}$ ) is large than the feed rate, then the theoretical surface finish is mainly a function of feed rate.

Table 4. Summary of ANOVA results.

\begin{tabular}{|c|c|c|c|}
\hline Source & P value & $\begin{array}{c}\text { Contribution } \\
\mathbf{( \% )}\end{array}$ & $\begin{array}{c}\text { Result } \\
\text { Interpretation }\end{array}$ \\
\hline Cutting Speed & 0.659 & 2.703 & Not significant \\
\hline Feed Rate & 0.054 & 91.599 & Significant \\
\hline Depth of Cut & 0.918 & 0.468 & Not significant \\
\hline Environment & 0.082 & 5.227 & Not significant \\
\hline
\end{tabular}


Figure 2 shows an interaction plot. These plots are used to provide an understanding of how the behaviour of one factor depends on the value of another. If the lines are parallel to each other, no interaction exists between the two factors, and if the lines are crossing, then there is an interaction. From Figure 2, it is evident that the significant factor (feed rate) has no interaction with the depth of cut and environment, while with the cutting speed slight, interaction exists at higher feed rate. Ozel at al. (Özel et al., 2005) illustrated that, as the feed rate is increased, the residual compressive stresses also increase and deepens the affected zone. This condition results in higher tangential forces which are unfavourable for surface finish. It is noted that tangential forces are the function of cutting speed and feed rate (Trent and Wright, 2000). This explained the statistical interaction of feed rate and cutting speed.

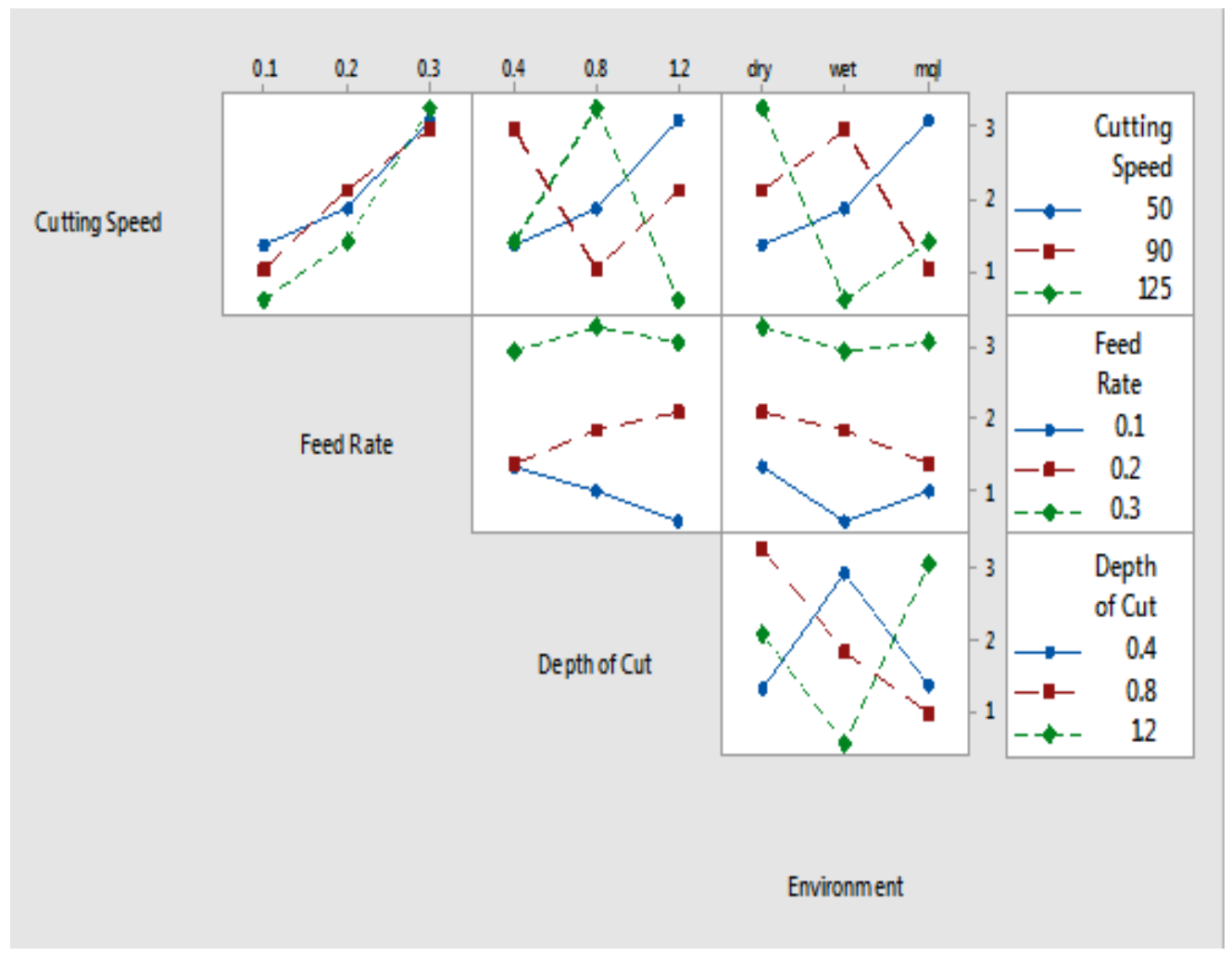

Figure 2. Interaction plot for Ra.

\section{Surface Roughness Estimation Model}

Based on the results of this study, first-order regression model was developed (using Minitab software) for forecasting the surface roughness in machining of AISI-410. Equation 1 represents the statistical model to forecast surface roughness as a function of cutting speed, feed rate, and depth of cut, provided that the cutting environment is flooded (wet).

$$
\mathrm{Ra}=0.029-0.00518 \text { Cutting Speed }+10.94 \text { Feed Rate }+0.017 \text { Depth of Cut }
$$

To attest the statistical model, the random set of experiments were performed to identify the relation between the estimated values and experimental values of Ra. Figure 3 shows the correlation diagram between experimental surface roughness and predicted surface roughness. $\mathrm{R}^{2}(0.9213)$ value of the fitted line indicates that a strong 
relationship exists between predicted and empirical values. Hence, it can be concluded that the statistical model is successful in estimating Ra values.

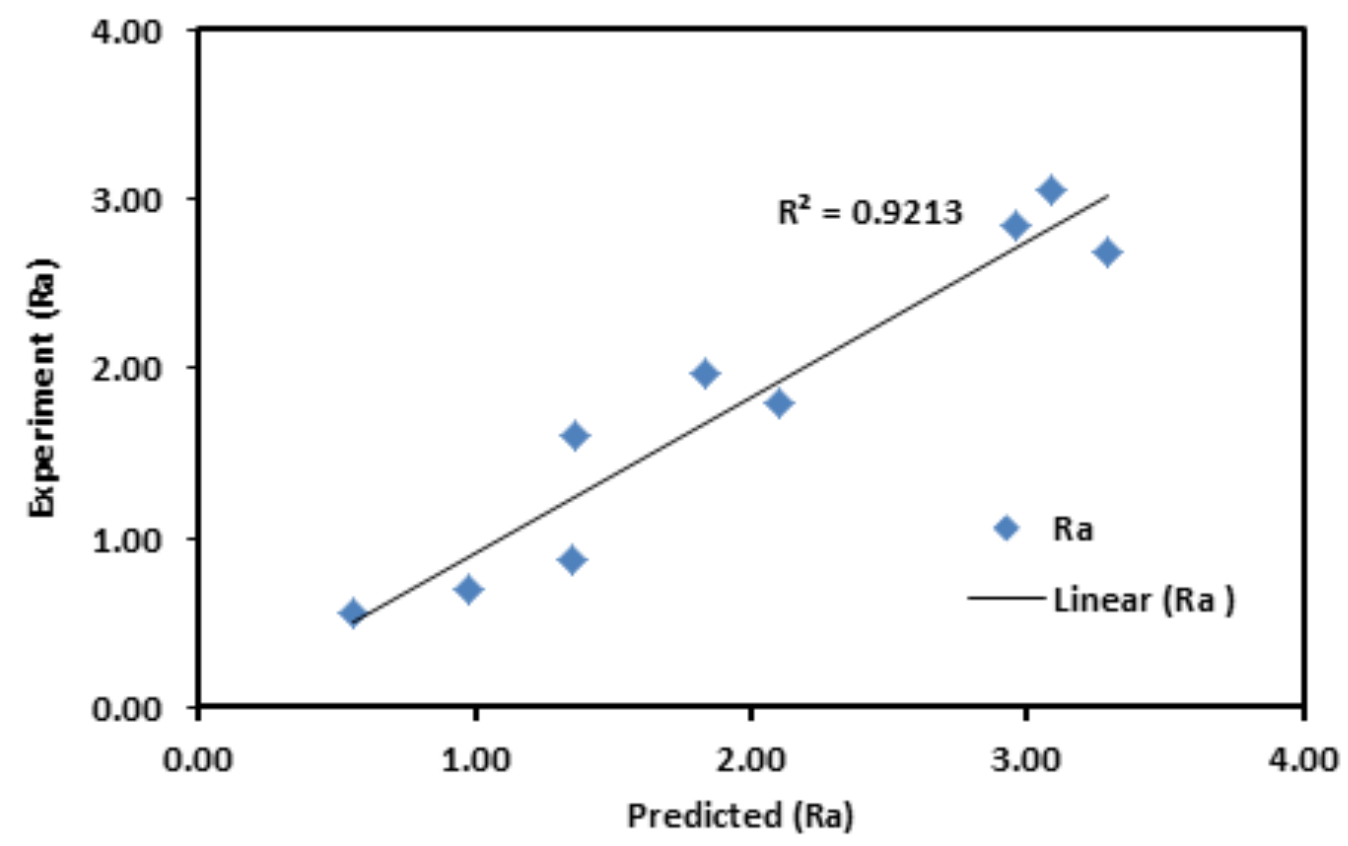

Figure 3. Correlation graph.

Table 5. Conformation tests results.

\begin{tabular}{|c|c|c|c|c|c|c|c|}
\hline & \multicolumn{3}{|c|}{ Cutting conditions } & \multicolumn{2}{c|}{ Ra ( $\mu$ m) } \\
\hline & $\begin{array}{c}\text { Speed } \\
(\mathbf{m} / \mathbf{m i n})\end{array}$ & $\begin{array}{c}\text { Feed rate } \\
(\mathbf{m m} / \mathbf{r e v})\end{array}$ & $\begin{array}{c}\text { Depth of } \\
\text { cut } \\
(\mathbf{m m})\end{array}$ & Environment & Empirical & Predicted & Error \\
\% & & 0.1 & 1.2 & wet & 0.441 & 0.526 & 12 \\
\hline 1 & 125 & 0.1 & 0.4 & wet & 0.5583 & 0.5516 & 3 \\
\hline 3 & 125 & 0.2 & 1.2 & wet & 1.788 & 1.789 & 1 \\
\hline
\end{tabular}

Also, conformation tests were performed on the optimum level and random values of the process parameter. Table 5 shows the obtained results. It is established that, for a reliable statistical result, error should be less than $20 \%$ (Zhang et al., 2007). From table 5, it is evident that in this study the maximum error of $12 \%$ is achieved. This reflects that the developed statistical model and optimization are in good agreement. 


\section{CONCLUSION}

The objective of this work is to investigate the suitable cutting environment and to optimize the process parameters to obtain best surface roughness in turning of AISI- 410 alloy. The empirical results were examined using Taguchi and ANOVA techniques. It was revealed that the adopted methodology is reliable in defining the effective and sustainable machining of AISI-410 alloy. The statistical analysis shows that the feed rate is the most influencing and significant control factor that affects the surface roughness (by 92\%). Therefore, it is recommended to adopt low values of feed rate in order to obtain a better surface finish in machining of AISI-410 alloys. From the analysis, it is also evident that the cooling environment is the next important parameter that affects surface finish. However, the contribution is only limited by $5.227 \%$, whereas the cutting speed and the depth of cut have a slight influence ( $2.703 \%$ and $0.468 \%$, respectively). The correlation coefficient of 0.9213 and conformation tests reveal that developed statistical model predicts surface roughness with the confidence level of $95 \%$.

\section{REFERENCES}

Astakhov VP. (2012) 4 - Environmentally friendly near-dry machining of metals. In: Astakhov VP and Joksch S (eds) Metalworking Fluids (MWFs) for Cutting and Grinding. Woodhead Publishing, 135-200.

Ay M. (2019) Effect of cutting parameters on surface roughness, tool temperature and vibration in turning of AISI 316 Ti stainless steel. Materials Testing 61: 71-79.

Çetin S and Kıvak T. (2017) Optimization of the machining parameters for the turning of 15-5 PH stainless steels using the Taguchi method. Materiali in tehnologije 51: 133-140.

Dassisti M, Chimienti M, Shuaib M, Badurdeen F and Jawahir IS. (2012) Sustainable Manufacturing: A Framework for Ontology Development. In: Seliger G (ed) Sustainable Manufacturing: Shaping Global Value Creation. Berlin, Heidelberg: Springer Berlin Heidelberg, 33-39.

Debnath S, Reddy MM and Yi QS. (2016) Influence of cutting fluid conditions and cutting parameters on surface roughness and tool wear in turning process using Taguchi method. Measurement 78: 111-119.

Deepak D and Rajendra B. (2016) Optimization of Machining Parameters for Turning of Al6061 using Robust Design Principle to minimize the surface roughness. Procedia Technology 24: 372-378.

Dwuletzki H. (2012) 9 - Replacement of metalworking fluids. In: Astakhov VP and Joksch S (eds) Metalworking Fluids (MWFs) for Cutting and Grinding. Woodhead Publishing, 368-388.

Evans R. (2012) 2 - Selection and testing of metalworking fluids. In: Astakhov VP and Joksch S (eds) Metalworking Fluids (MWFs) for Cutting and Grinding. Woodhead Publishing, 23-78.

Ghani JA, Choudhury IA and Hassan HH. (2004) Application of Taguchi method in the optimization of end milling parameters. Journal of Materials Processing Technology 145: 84-92.

Graff M. (2012) 10 - Disposal of metalworking fluids. In: Astakhov VP and Joksch S (eds) Metalworking Fluids (MWFs) for Cutting and Grinding. Woodhead Publishing, 389-402.

Karunya G, Ravikumar P, Krishna PG and Krishna PS. (2017) Optimization of the surface roughness by applying the Taguchi technique for the turning of AISI 304 austenitic stainless steel. International Journal of Mechanical Engineering and Technology 8. 
Lanz M, Mani M, Leong S, Lyons K, Ranta A, Ikkala K and Bengtsson N. (2010) Impact of Energy Measurements in Machining Operations. ASME Conference Proceedings 2010: 867-873.

Liyanage JP, Badurdeen F and Ratnayake RMC. (2009) Industrial Asset Maintenance and Sustainability Performance: Economical, Environmental, and Societal Implications. In: Ben-Daya M, Duffuaa SO, Raouf A, et al. (eds) Handbook of Maintenance Management and Engineering. London: Springer London, 665693.

Nalbant M, Gökkaya H and Sur G. (2007) Application of Taguchi method in the optimization of cutting parameters for surface roughness in turning. Materials \& Design 28: 1379-1385.

Özel T, Hsu T-K and Zeren E. (2005) Effects of cutting edge geometry, workpiece hardness, feed rate and cutting speed on surface roughness and forces in finish turning of hardened AISI H13 steel. The International Journal of Advanced Manufacturing Technology 25: 262-269.

Qasim A, Nisar S, Shah A, Khalid MS and Sheikh MA. (2015) Optimization of process parameters for machining of AISI-1045 steel using Taguchi design and ANOVA. Simulation Modelling Practice and Theory 59: 36-51.

Selvaraj DP and Chandramohan P. (2010) Optimization of surface roughness of AISI 304 austenitic stainless steel in dry turning operation using Taguchi design method. Journal of engineering science and technology 5: 293-301.

Shaw MC and Cookson J. (2005)Metal cutting principles: Oxford university press New York.

Singh T. (2019) Multi-response optimization in environment friendly turning of AISI 304 austenitic stainless steel. Multidiscipline Modeling in Materials and Structures 15: 538-558. Trent EM and Wright PK. (2000) Metal cutting: Butterworth-Heinemann.

Venkatesan K, Ramanujam R and Kuppan P. (2014) Laser assisted machining of difficult to cut materials: research opportunities and future directions-a comprehensive review. Procedia Engineering 97: 1626-1636.

Waseem O, Jeong J-R, Park B-G, Maeng C-S, Lee M-G and Ryu HJ. (2017) Hardness of AISI type 410 martensitic steels after high temperature irradiation via nanoindentation. Metals and Materials International 23: $1257-1265$.

Xavior MA and Adithan M. (2009) Determining the influence of cutting fluids on tool wear and surface roughness during turning of AISI 304 austenitic stainless steel. Journal of Materials Processing Technology 209: 900-909.

YUCEL E and GUNAY M. (2013) An Evaluation on Machining Processes for Sustainable Manufacturing. GAZI UNIVERSITY JOURNAL OF SCIENCE 26: 241-252.

Zhang JZ, Chen JC and Kirby ED. (2007) Surface roughness optimization in an end-milling operation using the Taguchi design method. Journal of Materials Processing Technology 184: 233-239. 